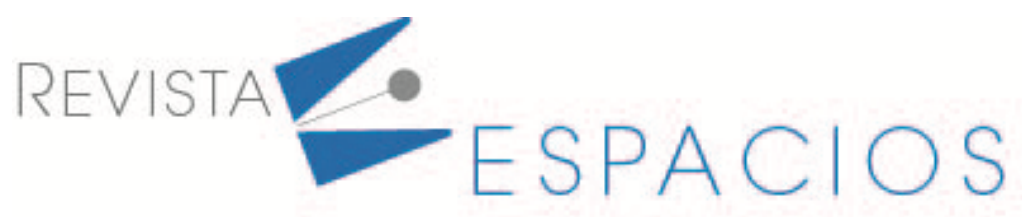

\title{
La dimensión ética del contador público en el caso Odebrecht
}

\section{The ethical dimension of the public accountant in the Odebrecht case}

\author{
HERNÁNDEZ-ROYETT, Javier ${ }^{1}$ \\ FRANCO-CAMPO, Diana P. ${ }^{2}$ \\ GALINDO-CÁRDENAS, Saúl ${ }^{3}$ \\ BERNAL PAYARES, Omaira ${ }^{4}$
}

\begin{abstract}
Resumen
El artículo descriptivo argumentativo, hace una recopilación teórica acerca del escándalo financiero Odebrecht en Latinoamérica, desde la dimensión ética del contador. El análisis considera una escala de funciones ocupaciones referentes a la ética profesional llegando a una interpretación de las relaciones personales e interpersonales del contador, concluyendo que se requieren responsabilidades de las empresas trasnacionales para que esas relaciones fluyan como compromiso de los contadores individualmente y de las partes vinculadas desde el sector público y privado.
\end{abstract}

Palabras clave: Odebrecht, contador público, ética, corrupción

\begin{abstract}
The descriptive argumentative article makes a theoretical compilation about the Odebrecht financial scandal in Latin America, from the ethical dimension of the accountant. The analysis considers a scale of functions, occupations referred to professional ethics, reaching an interpretation of the personal and interpersonal relationships of the accountant, concluding that they refer to the transnational authorities for these relationships to flow as a commitment of the accountants individually and of the related parties from the public and private sector.
\end{abstract}

key words: Odebrecht, public accountant, ethics, corruption

\section{Introducción}

El caso Odebrecht, constituye el escándalo de corrupción con las mayores dimensiones que se ha presentado en Latinoamérica, y que ha dado motivos al departamento de Justicia de los Estados Unidos para adelantar una investigación con la participación de una decena de países latinoamericanos. La cuestión ha alcanzado a traspasar tres continentes, ocasionando descalabros en las esferas económica y política de varios países del bloque latino.

Entonces Odebrecht S.A., es una compañía brasileña que dispone de un portafolio internacional variado de negocios, con acción en las áreas de ingeniería y construcción, inmobiliaria, infraestructura, energía,

\footnotetext{
${ }^{1}$ Docente investigador. Programa de contaduría pública. Universidad del Sinú Elis Bechara Zainum. Javier.hernandez@unisinu.edu.co

2 Docente investigador. Programa de contaduría pública. Universidad del Sinú Elias Bechara Zainúm.

${ }^{3}$ Docente investigador. Programa de contaduría pública. Universidad del Sinú Elias Bechara Zainúm.

${ }^{4}$ Docente investigador. Programa de administracion de empresas. Corporación Universitaria Rafael Nuñez. omaira.bernal@curvirtual.edu.co
} 
petroquímica, entre otros. Su operación está organizada a través de una estructura administrativa en Brasil y en 13 países más (Organización Odebrecht, 2018).

De manera que, en el desarrollo del objeto social de la empresa se han evidenciado actos de corrupción, fraude y manipulación financiera, dejando entrever un enlace de poder y sometimiento entre el gobierno corporativo y quienes tienen el deber profesional de medir, valorar y representar en la contabilidad las transacciones económicas y financieras tal y como sucede en la realidad, razones por las cuales entran en juego "los valores éticos al momento de comunicar los compromisos de una empresa y reflejar la forma cómo establece sus relaciones con los usuarios interesados" (Correa, Flynn, y Amit, 2004, p.17) desde el ambiente interno como también del externo (Sanroman, González, y Villa, 2015).

Aun así, con respecto al ambiente interno organizacional se da prevalencia a los niveles jerárquicos de mayor influencia y desde allí, quienes integran el gobierno corporativo de dirección y mando pueden ejercer su poder con propositos intencionados de desvirtuar la realidad en la contabilidad, según Martínez-Ferrero, VaqueroCacho, Cuadrado-Ballesteros, García-Sánchez, (2015), situándose como parte de las decisiones, las cuales, resultan de una planeación estratégica y un análisis de resultados dolosos.

De ahí que las alianzas en este caso de corrupción corporativa, tienen su génesis en el grupo de las compañías Odebrecht, y la vinculación de las empresas del Estado, consorcios, personas naturales y jurídicas, que intermedian en el manejo de los recursos públicos destinados a la inversion en infraestructura en diferentes países de la región conectadas, de forma directa e indirecta en las contrataciones de las obras públicas.

En consecuencia, estas contrataciones configuran la genesis de la contabilización de actos comerciales originados en transacciones de las partes vinculadas, respecto de las subcontrataciones, consorcios y otras figuras empresariales que desde la perspectiva financiera y contable se enmarcan en la teoría del aseguramiento de la información en las Normas Internacional de Auditoria/NIA 315 y NIA 550, para la detección de incorreciones de tipo material, normas que a la luz de los resultados, no se aplicaron por las personas a quienes correspondía ejercer los cargos de auditores, que en este caso se acreditan con la condición de contador público.

Sin embargo, esa actuación profesional del contador se distancia de su dimensión ética, por cuanto excluye la competencia técnica y las habilidades profesionales contempladas por la Federeacion Internacional de Contadores Públicos, (International Federation of Accountants IFAC) que trabaja para que, a partir de unos conceptos ético-morales, los contadores se encuentren por encima de la individualidad, a fin de resguardar el correcto ejercicio de la profesión, fundamentalmente por cuenta del interés social que permanece en juego.

En este orden, es indiscutible que al profesional de la contaduría, en desarrollo de sus funciones, le concierne interactuar con personas naturales y jurídicas o grupos de ellas, incluyendo los gobiernos de cada pais, lo cual compromete su responsabilidad en la preparación y certificación de la información financiera, asi como su veracidad.

Por consiguiente, en el caso Odebrecht, la informacion financiera se elaboró sin aplicar lo previsto en el código de ética de la IFAC (2018) en lo concerniente a las amenazas, con lo cual se materilizan los riesgos de incorreciones materiales al hacer la medición, valoración y representación contable de las llamadas coimas o pagos fraudulentos a fin de apropiarse y privilegiarse la asuncion de los contratos, actuación que pasó por alto el principio de integridad, plasmado como conducta a seguir por el profesional ejerciente de la contabilidad. Con ello se entrega un mensaje negativo y de inseguridad para las generaciones futuras (Fernández y Gutiérrez, 2013; Mejía, Mora, Montes y Montilla, 2014), inestabilidad que se le atribuye al desconcimiento e inaplicacion del codico de ética. 
Para cerrar, se anota que las orientaciones y teorías recopiladas en este documento, tienen un enfoque hacia la función del cargo del contador público en Latinoamérica, aunque en diferentes países tenga la denominación de contador, contador público o licenciado. Se trata del profesional que funge en la actividad financiera, de auditoría u otras áreas que favorecen la sostenibilidad empresarial y la seguridad patrimonial y, que está claramente establecida en el código de ética bajo la designación de las normas personales (IFAC, 2018); y por su puesto la reglamentación jurídica sobre la profesión contable que tenga cada país, la cual, como bien se indica en el marco conceptual sobre normas internacionales de información financiera, son autónomas y de obligatoria aplicación, a la par con los marcos normativos de autorregulación.

\section{Metodología}

La metodología utilizada en esta investigación es documental descriptiva, debido a que trata las características específicas del fenómeno estudiado a partir de fuentes secundarias (Hernández-Sampieri, Fernández-Collado y Baptista, 2014), obtenidas desde la verificación pormenorizada de revistas, libros, fuentes legales y normas nacionales e internacionales, destacándose el uso de fuentes periodísticas debido a la proyección y divulgación del tema; algunas de estas fuentes se citan sin detallar al autor individual, sino de la fuente periodística porque asi se detecta en la pesquisa de los datos. El enfoque es de tipo cualitativo e interpretativo conforme lo describen Hernández-Royett, y González-Díaz, (2016) para las ciencias contables.

Así como, el escrito parte de la revisión documental, exponiendo una escala de los niveles de desempeño del contador publico, vinculadas con las actuaciones éticas, a partir de cuya escala, discute su responsabilidad frente a la sociedad, las instituciones productivas y los estados.

En resumidas cuentas, los descriptores a partir de los cuales se obtienen los documentos incorporados de las diferentes bases de datos fueron Odebrecht, ética y contador público, con lo que se pueden plantear los siguientes interrogantes:

- ¿Qué está pasando con el desempeño de los profesionales de la Contaduría Pública en las empresas vinculadas con el caso Odebrecht?.

- ¿Dónde quedan registrados los comportamientos de la ética profesional de los mismos frente a la sociedad?

\section{Resultados}

\subsection{Desarrollo y discusión}

El ejercicio de la actividad política de donde se desprenden las conductas como la corrupción, puede explicarse desde la carencia de las condiciones necesarias que delimitan las actuaciones, que claramente están basadas en un accionar desprovisto de un valor ético, producto de la inversión del modelo sobre el cual se estructura el buen vivir que se basa en una concepción de bienestar general o bienestar común a un modelo de bienestar particular, lo cual redunda en perjuicio social, en detrimento de la calidad de vida de un colectivo social a causa de la visión antropocentrista que pone en primera línea los fines, pese a las consecuencias que se deriven de los medios utilizados para alcanzarlos.

Ante todo, los fundamentos que estructuran esas prácticas, están explicados según Bédard (2004), en permanecer firmes respecto a las consecuencias que se deriven de dichas acciones, con esto, la actividad humana se estudia, desde la praxeología, la cual se ocupa de las prácticas humanas individuales, que a su vez se bifurcan en dos fundamentos: las validaciones epistemológicas y los valores sociales y culturales que demarcan las orientaciones individuales y colectivas, las cuales surgen de la axiología. Por su lado, la axiología, se fundamenta 
en una disciplina filosófica mucho más amplia en su dimensión, es decir la ontología, la cual explica la construcción de la realidad que orienta a las actividades humanas.

En otras palabras, esta realidad soporta un fenómeno llamado corrupción, lo cual comprende una antítesis de la concepción filosófica de la axiología. La ontología estudia al ser humano y contiene a la axiología, que estudia la natraleza de los valores. De ellas depende la construcción de la realidad del sujeto, su forma de percibir el mundo y orientarse en él. Esto es lo justo para afirmar que las personas cuyas acciones están basadas en ontologías de la corrupción y efectivamente, conductas antropocentristas donde prima el bienestar y fines particulares a coste del bienestar colectivo, evidencian un claro desfiguramiento de la relación praxiologíaaxiología; es decir, las prácticas corruptas evidenciadas en el caso Odebrecht, permiten demostrar la materialización de la mencionada antítesis.

En consecuencia, para De Felipe (2010), la corrupción deviene de una anomania política, la cual no depende de las corrupciones personales, de lo que se puede colegir que, aunque las acciones corruptas individualizadas no dejan de ser una conducta grave y cuestionable, lo es en menor medida si se le compara con un todo, o con una organización estructurada a partir de la relación de poder y unidad política, lo cual, a su vez, le da fuerza al sistema debido a la realidad del entorno cultural. Ese entorno que tiene una cosmovisión de competencia y de ejercicio del poder con fines de control y dominio económico a cualquier precio.

En ese orden de ideas, Odebrecht, como agente externo a la estructura política de los países donde opera, es la persona jurídica responsable de la ejecución de la inversión, lo que en derecho se conoce como la capacidad jurídica de la empresa, gracias al sustrato sobre el que está construido el edificio político permeado por ontologías corruptas.

\subsubsection{Del desempeño profesional del contador}

El profesional en contaduría, lejos de lo que a veces se piensa, no es un sujeto dedicado exclusivamente a las pesquisas de cifras y la incautación de condiciones erradas o no conformidades en los estados financieros, sino que durante el desempeño participa en un nuevo esquema de relaciones personales y empresariales que aportan valores a las empresas mediante el liderazgo y la solución de problemas.

Es decir, esas relaciones demandan el buen tratamiento de los recursos financieros como un componente de creación de valor en su condición de consultor corporativo (Corral, 2009). Su papel en este sentido, no es distinto al que se vislumbra en las pequeñas y medianas empresas (Linares y Suárez 2017), solo que, en el primer caso la dimensión requiere de un mayor horizonte de responsabilidades que en el segundo.

Puesto que, para orientar y disgregar la responsabilidad ética del contador público en este estudio, se consideran tres escalas o niveles de desempeño del profesional en contaduría: 1 . Ayudante de registro de libros y generador de informes. 2. Asesor externo, responsable de hacer recomendaciones y de la seguridad tributaria de la empresa y 3 . Agregador de valores corporativos en correspondencia con las demandas sociales de los interesados.

De acuerdo a esto, los tres niveles se validan descriptivamente mediante una pirámide de reconocimientos sociales y profesionales de las funciones que desempeña el contador, partiendo desde las actividades básicas hasta sus acciones más consolidadas en el ejercicio profesional, lo cual se aprecia en la Figura 1. La pirámide de niveles de desempeño del contador público, asciende a partir de las herramientas disponibles para el análisis de la información (Espinoza, 2016) en los diferentes espacios y tiempos donde este desarrolla sus actividades, siendo conscientes del ecosistema estratégico y la necesaria evolución que concierne a este profesional para que no infrinja en la sociodicea contable que plantea Franco (2016), según la cual "sus prácticas profundicen su compromiso como saber estratégico al servicio de un poder dominante" (p. 272). 
Por tanto, las tres escalas conforman el cúmulo de conocimientos, actuaciones y reconocimientos sociales del contador a partir de la idoneidad colectiva de la profesión.

\section{Figura 1}

Pirámide de niveles de desempeño del contador público
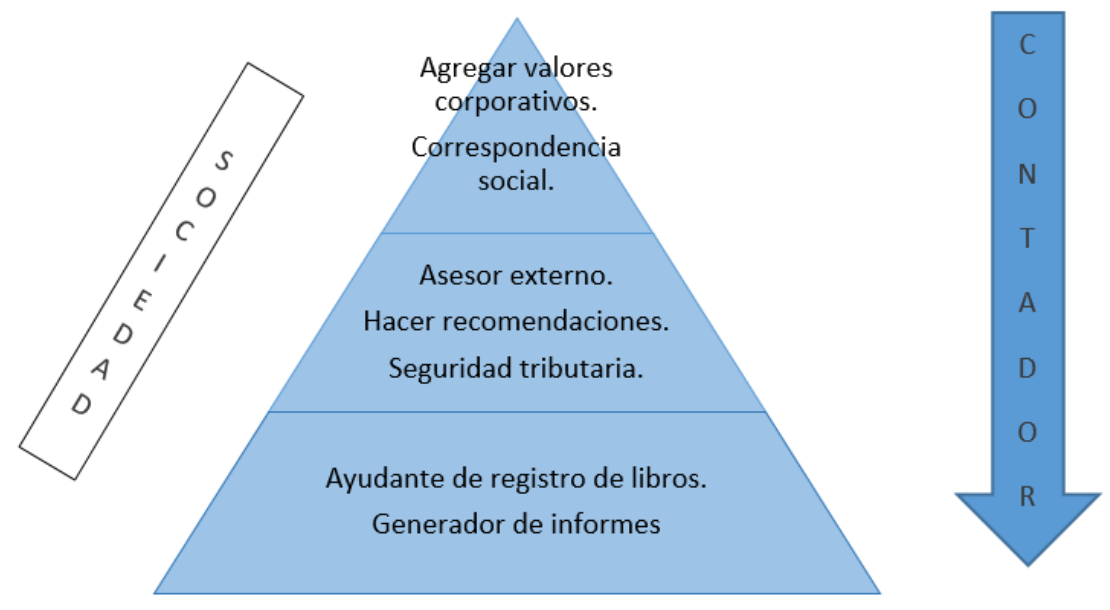

Fuente elaboración propia, 2019

Es así como, el primer nivel de la escala, es aquel que está sujeto al imaginario colectivo, según el cual el profesional en contaduría es un ayudante del registro de los libros y generador de informes. Este concepto de desempeño profesional ha sido superado en muchos espacios, debido a las propias competencias profesionales individuales y por otra parte, en razón de los alcances sobre la idoneidad colectiva que ha ganado la profesión.

De acuerdo con esto, la contabilidad no tiene que ser necesariamente "...un instrumento del registro operacional; es, en su componente técnico-tecnológico, un medio para representar la realidad económica de una organización, e incluso orientarla" (Alberto y Salazar, 2006).

Entonces resulta que, según la visión que propone el primer nivel, se puede considerar que la ejecución de informes, no constituye precisamente la expresión de los resultados concretos de las operaciones de la organización, sino la consecuencia de las acomodaciones del responsable de ellas, mediante el ejercicio de prácticas fraudulentas (Robazo, 2017), que no corresponden a la realidad que supone la fe pública.

Asimismo, la segunda escala de la pirámide, asume que el contador público es un asesor interno o externo, encargado de hacer recomendaciones y proporcionar seguridad tributaria a los socios y a la administración de los negocios. Las dos escalas referidas hasta ahora, personifican la existencia de una visión simplificada del sistema de datos contables, de sus procesos y sus resultados, encaminada principalmente a la preparación y archivo de los documentos obligatorios con la intención básica de satisfacer a los socios y de efectuar el cumplimiento de las obligaciones impuestas por las administraciones de los tributos, todo ello liderado por un contador multifuncional.

Mas aún, el tercer nivel representa la actividad colaborativa de las personas que generan la información con sinergia, (Vargas, Cruz, Gatica, y García, 2015), para plasmarla los informes financieros y no financieros, necesarios para los usuarios de la contabilidad, y en la medida que esa informacion sea relevante, sera útil para la propia imagen corporativa, o en su defectos si los registros e informes riñen con la realidad, ese valor agregado se convierte en el elemento base de genracion de reproche social dado el alcance de la confianza publica. 
Se puede extraer de lo dicho, que en la primera escala existen habilidades de maniobra de datos y algunas competencias técnico-profesionales, en la segunda y la tercera predomina el dominio de los procesos cognoscitivos sobre los sistemas de información, habilidades mentales y competencias profesionales (Roncancio, Mira y Muñoz, 2017).

Con todo esto, la misión del profesional contable debe ir más allá de un ejercicio comprometido con las acciones teorizadas, a ser un contador transversal que se ajusta a las realidades sociales, como propone (Franco, 2018) respecto a un pensamiento contable latinoamericano y Ovallos, Álvarez y Miranda (2017) al analizar la prospectiva ética del contador público desde las Normas Internacionales de información Financieras (NIIF), al referirse a los sujetos de la sociedad comprometidos y el desarrollo humano.

En este sentido la responsabilidad de la educación contable, (Morelo y Torres, 2016) y la incorporación de las normas de auditoria ambientales (Galindo y Franco, 2016) constituyen componentes que se deben explorar.

Resumiendo, en la pirámide se interpreta un enfoque desde las diferentes esferas de la sociedad, con fundamento en los reparos mismos del discurso del contador, según el cual, su actuación en el ejercicio profesional se ubica en posiciones vulnerables a los temas de corrupción, que pueden tener su asiento en la dispersa y compleja ubicación en la pirámide.

Esto conlleva a un laberinto normativo respecto a la responsabilidad del contador público (Hernández-Royett, Franco, Canabal, Sánchez, y D’Andreis, 2017), 'por cuanto la función del contador público, está contextualizada en las organizaciones, desde los tres niveles, guarda relación con la sociedad y la percepción que esta tiene de él, lo cual apunta al perfil relacional de la contabilidad, considerado como una contribución a las discusiones que le dan entidad a esta profesión.

\subsubsection{Perfil relacional de la contabilidad}

Preexisten unos antecedentes fraudulentos y de corrupción a grandes escalas y niveles del poder, en contrapeso a las consideraciones de nuevos escenarios epistemológicos de la contabilidad que abordan temas sobre la naturaleza, la cultura, la población y la economía, bajo el concepto de una "teoría contable alternativa centrada en la sociedad y no en las finanzas" (Franco, 2018), que contiene como eje central las relaciones con el entorno, cuyos componentes indiscutiblemente le concierne y hacen parte de la sociocontabilidad.

Por tanto, el concepto "sociocontabilidad" hace parte de las propuestas emergentes de la contabilidad que privilegia un entorno de economía social cuyo fundamento principal no está expresado como en las empresas privadas tradicionales en la lógica del capital (Chávez y Monzón, 2018), sino mediante un acuerdo social relacional que tiende a la recuperacion de la cultura y de la ética, asi mismo a la teorización de las realidades complejas (Lukomski y Mancipe, 2008) de los negocios con efectos sociales ambientales y económicos.

\subsubsection{Caso Odebrecht y demandas civiles}

El proceso de la empresa trasnacional Odebrecht, es uno de los temas de corrupción más trillados en los últimos años, lo cual ha generado controversias sobre los comportamientos éticos de los funcionarios de las organizaciones privadas y públicas en el mundo. La cuestión ha ocasionado reveses en las esferas económica, política y legal de varios países del bloque latino, tales como Brasil, Colombia, Perú, Ecuador, Argentina, Panamá, República Dominicana, Venezuela, Guatemala, entre otros (Cortes, 2017).

En esta sección, se registran algunos acontecimientos reportados en la demanda civil conocida a través del departamento de Justicia de los Estados Unidos en la que, el señor Peter Kaltman, de manera individual y en nombre de "todos los demás situados de manera similar" realiza una demanda de acusación a Petroleo Brasileiro SA - Petrobras, con fundamento en las exploraciones llevadas a cabo por los firmantes del demandante. La acción 
trata el caso1:14-cv-09662-JSR. En la acción civil y en este estudio, no se relacionan procedimientos penales; según la información obtenida de ella, se presentaron documentos tales como:

"comunicados públicos, declaraciones de prensa, presentaciones ante la bolsa de valores, conferencias de analistas.

En cierto modo, el asunto de fondo trata de la compra de Acciones de Depósito Americanas ("ADSs") de Petrobras en un Intercambio de Estados Unidos, desde el 20 de mayo de 2010 hasta el 21 de noviembre de 2014" (Civil action No14, 2014).En dicha acción, el demandado se caracterizó por su insistencia en negar los hechos, haciendo "declaraciones falsas y engañosas, omisión de hechos" (Civil action No14, 2014) y tergiversación de otros.

Por lo tanto, lo ocurrido en estos sucesos de fraude y maniobras financieras, se funda en el favorecimiento mediante pagos ilegales a funcionarios de grandes obras de infraestructura, algunas de las cuales se resumen en la Tabla 1. Indicando el país, el año de inicio y las acciones legales de tipo civil obtenidas.

Tabla 1

Países con denuncias por contratos ilícitos con la empresa Odebrecht

\begin{tabular}{|l|l|l|l|}
\hline \multicolumn{1}{|c|}{ País } & \multicolumn{1}{|c|}{ Obra } & \multicolumn{1}{|c|}{$\begin{array}{c}\text { Año de } \\
\text { inicio }\end{array}$} & \multicolumn{1}{c|}{ Notas legales } \\
\hline EE UU & $\begin{array}{l}\text { Compra de Acciones de Depósito } \\
\text { Americanas (ADA) }\end{array}$ & 2014 & $\begin{array}{l}\text { Demanda civil, caso1:14-cv- } \\
\text { 09662-JSR Archivado el } \\
12 / 08 / 14 .\end{array}$ \\
\hline Colombia & $\begin{array}{l}\text { Ruta del Sol, el eje vial que une Bogotá } \\
\text { con la costa atlántica } \\
\text { Adición de la Transversal Ocaña- } \\
\text { Gamarra }\end{array}$ & 2009 & $\begin{array}{l}\text { Audiencia pública de } \\
\text { adjudicación entre el 14 y el 15 } \\
\text { diciembre de 2009. } \\
\text { Otrosí No 6 del 14 de marzo de } \\
2014 .\end{array}$ \\
\hline Perú & Línea 1 y 2 del Metro de Lima & 2009 & NE \\
\hline Argentina & $\begin{array}{l}\text { Ferrocarril Sarmiento } \\
\text { 7 obras, adjudicadas entre los } \\
\text { años 2005 y 2013 }\end{array}$ & $\begin{array}{l}2010 \\
2005-\end{array}$ & $\begin{array}{l}\text { NE } \\
2013\end{array}$ \\
\hline Ecuador & $\begin{array}{l}\text { Metro de Quito. } \\
\text { Consorcio Odebrecht - Acciona }\end{array}$ & 2015 & $\begin{array}{l}\text { Tras las revelaciones de la } \\
\text { justicia de EEUU, se suspendió } \\
\text { la operación. }\end{array}$ \\
\hline Panamá & $\begin{array}{l}\text { Proyectos Sistema Remigio Rojas, } \\
\text { Cinta Costera 1 y Medden - Colón } \\
\text { Otras obras }\end{array}$ & $\begin{array}{l}2006- \\
2009 \\
2009-\end{array}$ & $\begin{array}{l}\text { Contrato de obra No. DAL-002- } \\
\text { ADM-2006 }\end{array}$ \\
\hline Benezuela & $\begin{array}{l}\text { Metrocable Mariche / La Dolorita } \\
\text { Metro Caracas Guarenas-Guatire } \\
\text { Otros tramos del metro Caracas. }\end{array}$ & 2016 & 2004 \\
\hline
\end{tabular}

Fuente: elaboración propia de fuentes periodísticas (2019). NE: no encontrado

En efecto, La Tabla 1 expresa las principales obras de infraestructura por las cuales está vinculada la empresa con proyectos que han sido demandados, a los que se les siguen procesos de tipo civil en los gobiernos de Latinoamérica entre los años 2004 a 2018. Se inicia con Estados Unidos debido a que este país dió apertura al proceso judicial por la detección del fraude a través de una demanda civil según caso1:14-cV-09662-JSR. 
Entonces, en Colombia este conglomerado económico, ejecuta la ruta del sol, uno de los proyectos más ambiciosos de infraestructura vial que une al centro del país con la Costa Caribe. En el caso de la adición de la obra de la Transversal Ocaña-Gamarra el otrosí radicado con número 6 se pactó el 14 de marzo de 2014, con siete meses de anticipación de la realización del Consejo Superior de Política Fiscal (CONFIS) y del Consejo Nacional de Política Económica y Social (CONPES), lo cual indica que no se produjeron las autorizaciones ni la disponibilidad presupuestal del estado (Betín, 2018).

Por su parte la compañía de auditoria PricewaterhouseCoopers (PWC), comprometida con la revisión de las cuentas de la empresa Norberto Odebrecht y KPMG, que estaba vinculada a la construcción de la ruta del sol, tras conocer que el empresario Marcelo Odebrecht confesó, en colaboración con la justicia de Estados Unidos, el pago de sobornos en Colombia, cercanos a US\$11,5 millones, inicia una revisión de cuentas desde 2008, cuyas irregularidades, informó a la Superintendencia de Sociedades de ese país mediante las comunicaciones del 14 y 28 de marzo del 2017 (Vargas, 2018).

Ademas, el 6 de septiembre de 2017, mediante un oficio de PricewaterhouseCoopers renuncia al cargo de revisor fiscal en Odebrecht, así como las personas naturales designadas. Todo esto generado a partir de una disputa por la entrega de información que para PWC no se había suministrado y para los directivos de Odebrecht estaban al alcance (Dinero, 2017). En ese estado de cosas, la firma auditora no refrenda los estados financieros que los entes fiscalizadores requieren para las investigaciones, por lo que la Superintendencia de Sociedades les abre pliego de cargos.

Es así como, la empresa decide inactivarse en Colombia cuando capturan a su representante legal, lo que causa el desplome de las acciones del grupo AVAL, el cual es socio de Odebrecht en un proyecto de carreteras (Venegas, 2018).

Para colmo, un caso análogo sucede con el Consorcio Metro de Lima en Perú, el cual se caracteriza por no presentar el análisis de gastos generales, "transgredió el derecho de vías y no cumplió con las exploraciones a la profundidad mínima exigible". Los informes de auditoría indican que se hicieron modificaciones al trazo propuesto al inicio del proyecto, consiguiendo, aumentar la suma de la obra de US\$ 583, 480,359 a US\$ 900, 610,616 . El proyecto fue liquidado en US\$885, 154,813 (Semenaeconomica.com, 2019). Adicional se registran retrasos en las inversiones obligatorias y entrega de 13 de 73 áreas de concesión con vencimiento en noviembre de 2016 (Contraloría General de la Republica de Perú, 2018).

Por otro lado, el soterramiento del tren sarmiento en Argentina, es una obra de gran infraestructura que adelanta la construcción de 32,75 kilómetros de túneles que disponen de 15 estaciones en Buenos Aires (Perfil, 2016), entregada mediante una licitación adjudicada en 2008 a la empresa italiana Ghella, la brasileña Odebrecht e lecsa, empresa en cabeza del primo del presidente argentino Macri. La empresa constructora brasileña reconoció haber pagado coimas por US\$35.000.000 en este país entre los años 2007 a 2014 (Delfino, 2018).

Adicional a esta obra, desde 2005 hasta 2013 se han ejecutado otras como la Ampliación de los gasoductos, la potabilización, la planta de reformado catalítico para la producción anual de naftas, obtención, industrialización y distribución de cloruro de potasio en Rio Colorado, certificación en Seguridad, Medio Ambiente y Salud para el área de Negocios Internacionales de Petrobras, ampliación de la capacidad de transmisión y distribución de energía en el norte, sur y costa atlántica de la provincia de Buenos Aires.

Igualmente, en Ecuador, O Globo indica que la asociación Rivera y Glas rindió ganancias millonarias a Odebrecht (El Universo, agosto 3 de 2017), entre las obras que la empresa hiciera con la hidroeléctrica Manduriacu, el trasvase Daule - Vinces, el terraplén de la Refinería del Pacífico, la construcción del acueducto La Esperanza, y el Poliducto Pascuales-Cuenca. Este país pide colaboración penal a los Estados Unidos para avanzar en las investigaciones y prohíbe la contratación con la compañía cuestionada. 
A esto se añade en Panamá, el proyecto Sistema Remigio Rojas, Cinta Costera 1 y Medden - Colón, que inicia en 2006, vinculaciones en las investigaciones con el Saneamiento de la Bahía de Río Caldera, Renovación Urbana de Curundú, Línea 1 del Metro, Cinta Costera 2, Cinta Costera 3, Mejoramiento vial en Chanis, expansión del Aeropuerto de Tocumen, carretera Santiago-Viguí, Tercera Línea de Transmisión Eléctrica y camino de acceso a la Zona Libre (Perea, noviembre 29 de 2018). (Ver tabla 1)

También se detectó, el proceso legal en Brasil, como en Estados Unidos, por transacciones, a través de una red cambistas, acerca de "50 órdenes de detención preventiva o temporal, ha puesto en marcha más de 50 acciones penales y ha condenado alrededor de 100 personas, marcando un antes y un después en la historia de Brasil" (Barón, septiembre 16 de 2016).

Es así como, en Venezuela se mencionan obras como Metrocable Mariche / La Dolorita Metro Caracas GuarenasGuatire y otros tramos del metro Caracas, conociendo de 11 obras inconclusas.

Hasta aquí, se han enunciado una variedad de contratos realizados por la compañía Odebrecht con los gobiernos de algunos de los países con los que contrató bajo estas modalidades ilegales. Además se agregan datos explícitos que evidencian la participación de los contadores operando, por acción o por omisión en el ejercicio de sus funciones. (Hernández-Royett, 2016)

\subsubsection{Participación multilateral - trasnacional}

El comportamiento del Contador Público bajo los efectos que ocasiona la presión de otras partes interesadas (NIA 550) tiene vínculos con la ética profesional, lo cual se evidencia en un estudio realizado a 664 personas contadores de 23 países por la Federación Europea de Contables y Auditores para Pyme (EFAA) por sus iniciales en inglés, el cual indica que el "64\% (416) de los encuestados confirmaron que, durante su carrera profesional, habían sido sometidos a presión para actuar en contra” de la ética profesional (Lang, Karmanska, y Jarvis 2016, p. 4).

No obstante, con estos estudios la EFAA tiene la intención de compartir información para concienciar sobre la cuestión ética que pone en la balanza el buen ejercicio de esta profesión.

De un lado están las coacciones causadas por terceros, que pueden ser blandas mediante una sutil intervención o también pueden ser imperativas. Lang, Karmaska \& Jarvis, (2017) consideran que la fuente de la presión surge desde los superiores internos y los externos de la empresa, lo cual refleja la vinculación de cómplices internos en los fraudes presupuestales de las entidades, aunque participe con el movimiento de toda la maquinaria de poder y de influencias externas.

Del otro lado de la balanza se encuentran las buenas prácticas éticas que le hacen contrapeso. Ahora bien, las consideraciones éticas más recientes, funcionan vinculando con mayor proximidad el paradigma de la contabilidad social relacional o sociocontabilidad relacional, el cual deja ver un mayor peso de este último lado de la balanza.

Ademas, otro propósito trasnacional conocido es el papel constructivo del Vaticano y la Federación Internacional de Contadores (IFAC) a partir de un llamado de este contra el fraude y la corrupción. Es fácil entender que más allá de tratar vínculos financieros y contables, toca los asuntos sociales y de la moral colectiva e individual, fue por ello que el Papa Francisco, realizó una invitación a los contadores profesionales que concurrieron al Congreso Mundial de Contadores de 2014 en Roma a una audiencia con la presencia de la Federación Internacional de Contadores (IFAC) y demás líderes de la profesión de todo el mundo (IFAC, 2016).

Del mismo modo, esto ha traído consigo la vinculación de naciones para identificar necesidades, con la participación de las organizaciones profesionales y socios estratégicos como Departamento para el Desarrollo 
Internacional del Reino Unido (DFID), el Banco Mundial, el Fondo Monetario Internacional y otros bancos de desarrollo. Se incluyen controles y equilibrios efectivos para supervisar y hacer cumplir las políticas antisoborno y anticorrupción, incluyendo recomendaciones para el G-20, que trata sobre la confianza y la integridad (IFAC, 2016). Todo esto le apuesta a una regulación inteligente, mayor transparencia en los contratos y crecimiento inclusivo que permita devolver la confianza en las instituciones y suscitar el perfeccionamiento económico mundial.

De este modo, el consejo sobre gobernanza presupuestaria de la Organización para la Cooperación y Desarrollo Económico $(\mathrm{OCDE})$ constituye un referente internacional sobre principios de buena gobernanza apreciable en la Figura 2 que trata la precisión en los registros contables de las entidades del gobierno.

Figura 2

Diez principios de buena gobernanza

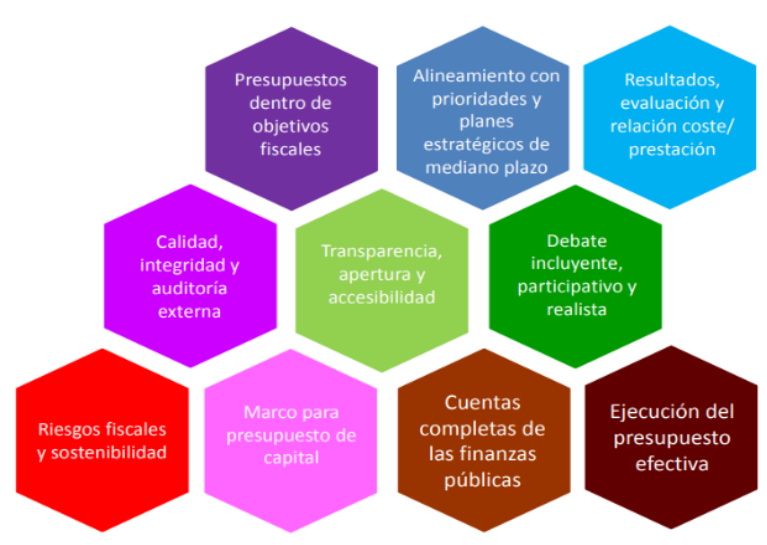

Fuente: (OCDE, 2015, p. 2)

Igualmente, expresa la contabilización minuciosa y correcta en el presupuesto de todos los ingresos y gastos del gobierno nacional, sin omitir ni ocultar cifras podrán aplicar restricciones limitadas con determinados fines de seguridad nacional y otros fines legítimos), y con leyes, normas o declaraciones que garanticen la veracidad del presupuesto y que restrinjan el uso de mecanismos fiscales extrapresupuestarios (OCDE, 2015, p. 11).

Así, los organismos trasnacionales a partir de la realidad que se vive en el mundo actual, encausan la adquisición de conciencia sobre la necesidad de la sociocontabilidad, mediante una postura responsable (Franco, Arrieta y Muñoz, 2015) que debe practicar el contador público para la seguridad de la información y la trasparencia en los datos contables. Han desarrollado acciones y documentos que proporcionan lineamientos para encaminar esta disciplina. La intención en este documento es vislumbrar algunos de los alcances de estos órganos como elementos conceptuales y metodológicos para la construcción de una metodología para la sociocontabilidad relacional.

\section{Conclusiones}

Los problemas financieros del caso Odebrecht en los países latinoamericanos, vistos desde la dimensión ética del contador son de trascendencia internacional con afectación a la estabilidad política y la gobernanza de una decena de países latinoamericanos, con la participación ilegal de diversos funcionarios de la empresa pública y del sector privado. Además, la vinculación de muchas profesiones, con la indiscutible participación de los contadores, lo cual se puede confirmar a través de las investigaciones realizadas por la justicia de los Estados y las sanciones impuestas por esta y por los órganos de la profesión contable. 
A pesar de los diferentes organismos que emiten normas legales y de autorregulación de la profesión contable, que guían el correcto accionar en las actividades propias de la profesión, es la persona del contador público la que debe valorar el concepto de dignificación de la profesión y el alcance del riesgo social y del interés público que genera materializar las amenazas de interés propio, abogacía, familiaridad, autorevisión e intimidación, como producto del desacato a los principios de integridad, objetividad, comportamiento, competencia y diligencia profesional.

Los fraudes aquí tratados corresponden principalmente a acontecimientos ocurridos durante las últimas dos décadas, relacionados con la realización de obras de infraestructura en Latinoamérica entre entidades oficiales, la empresa Odebrecht y otras empresas subcontratadas que, en algunos casos, figuran como partes vinculadas.

Teniendo en cuenta el paradigma de la sociocontabilidad desde una perspectiva de las relaciones de las personas, los contadores tienen unas responsabilidades claras y numerosas, expresadas en las diferentes regulaciones y estándares internacionales, adicional a ello, adquieren un compromiso social y relacional, fundados en que la normatividad del código de ética de este profesional que indica de manera explícita, entre sus competencias profesionales las relaciones personales e interpersonales, a las cuales les da alcance la sociocontabilidad relacional que propone temas sobre la naturaleza, la cultura, la gente y la economía en su conjunto, considerando las relaciones entre los otras personas naturales o ficticias.

Las síntesis aportadas sobre los compromisos del contador y su participación en este caso de corrupción, permiten hacer reflexiones que destacan el papel que puede desempeñar en la lucha contra los fenómenos de corrupción. Esto conlleva a repensar lo que se viene haciendo y reivindicarse, tras una revisión inmensamente consiente sobre la superior necesidad de forjar y presentar informes de alta calidad, diferentes a aquellos que no representan las realidades financieras de las empresas comprometidas en el caso estudiado. Los cantadores adquieren responsabilidades por la preparación y certificación de las cifras expresadas en los estados financieros con razonabilidad; los auditores tienen responsabilidades en la verificación de que estas cifras no tengan errores de incorrección material a partir del conocimiento de la entidad y el entorno en que se desenvuelve (Norma Internacional de Auditoría, NIA 315).

Las entidades transnacionales han interpretado la necesidad de vincularse en los asuntos de corrupción que afectan la ética y la economía mundial; por ello se están haciendo llamados globales desde diferentes órganos de gobernanza, en la búsqueda de llegar a acercamientos para concertar trabajos conjuntos que permitan tomar medidas para una mayor transparencia y control en las finanzas corporativas y los presupuestos de los Estados. Esta tendencia es una especie de conciencia universal que proporciona mayor seguridad al contexto contemporáneo en que se desenvuelven los Estados hoy día, aunque no prospera con la premura que se demanda.

La prensa investigativa juega un papel que establece sus resultados, transformándose en un fuerte instrumentos de comunicación en estos temas que abordan diversas esferas de corrupción, debido a que el periodismo toma iniciativas que pueden ser contundentes al denunciar e informar públicamente, lo que es una herramienta para el desarrollo de una cultura ciudadana transparente que ayuda en la construcción de agendas con intereses comunes y la participación de los grupos de interés; del mismo modo, se sabe que la prensa tiene vinculados económicos en todo el mundo que también cae en manos de las redes de corrupción pudiendo faltar a sus compromisos éticos.

\section{Recomendaciones}

Los Estados deben establecer unos mecanismos más seguros a nivel trasnacional, que proporcionen garantías respecto la seguridad financiera a los mismos y den garantía del cumplimiento de las formalidades legales, 
incluyendo aquellas que son de tipo ético. Véase que un escándalo de corrupción de esta envergadura puede traer catástrofes económicas que comprometen no solo las finanzas de los Estados participantes, sino su estabilidad política y financiera, con graves consecuencias de credibilidad, pudiendo ocasional descalabros financieros de talla mundial.

Aunque los organismos trasnacionales han establecido lineamientos para promover la trasparencia y evitar la corrupción en los países del orbe, no hay indicadores contundentes a favor, específicamente en Latinoamérica, lo cual corrobora la necesidad de seguir fortaleciendo estas acciones. El asunto concierne a la vinculación global de una cultura social consensuada, ecuménica, necesaria para salvaguardar la seguridad de las futuras generaciones en un mundo cada día más universalizado.

Desde la sociocontabilidad, se deben abordar las competencias relacionales, a las que está obligado el contador para favorecer los principios éticos que aporten a la filosofía del pensamiento contable, en una intensión que va más allá de las especulaciones para aumentar el capital inmediato de las empresas, y que principalmente se tengan en cuenta los componentes culturales, económicos y ambientales como instrumentos para el crecimiento empresarial, con especial atención al futuro. Este componente generacional de la sociocontabilidad, aquí se observa y se circunscribe desde las relaciones del contador, es decir, sus relaciones personales e interpersonales para asegurar su efectivo desempeño social con los individuos y con las empresas.

Respecto de la academia, la investigación contable debe fortalecer aspectos diferentes de la técnica contable y redireccionar los temas de teorización, como un mecanismo de defensa de la profesión por cuanto es una ciencia que no se focaliza sobre sumas y restas o sobre la manipulación de un software contable, la contaduría es mucho más que eso y el contador agrega valores corporativos a las empresas, por lo cual casos como Odebrecht, necesariamente deben llamar la atención a los académicos, a las facultades y programas de contaduría, para que desde el proceso de entrenamiento y formación del contador se haga un trabajo diferente y sistémico, que se aparte del paradigma de la linealidad cartesiana.

\section{Referencias bibliográficas}

Alberto, C., y Salazar, M. (2006). Dimensión del paradigma de utilidad en el mundo globalizado y su relación con la contabilidad, Libre empresa V. 7(2). 43-62.

Barón, F., (septiembre 16 de 2016). 7 preguntas y respuestas para entender la operación Lava Jato. CNN. Brasil. Recuperado de https://cnnespanol.cnn.com/2016/09/26/7-preguntas-y-respuestas-para-entender-laoperacion-lava-jato/

Bédard, R. (2004). Los fundamentos del Pensamiento y las Prácticas Administrativas. 2- la trilogía administrativa. AD-Minister 4 pp. 80-108

Betín, T. (enero 2 de 2018). Lo que encontró la Contraloría en la vía Ocaña-Gamarra. El Heraldo. Recuperado de https://www.elheraldo.co/colombia/lo-que-encontro-la-contraloria-en-la-ocana-gamarra-442670

Bolivia, 11(11), 17-35. Recuperado en 11 de marzo de 2020, de http://www.scielo.org.bo/scielo.php?script=sci_arttext\&pid=S2071-081X2016000100002\&lng=es\&tlng=.

Chávez, R. y Monzón, J. (2018). La economía social ante los paradigmas económicos emergentes : innovación social, economía colaborativa, economía circular, responsabilidad social empresarial, economía del bien común, empresa social y economía solidaria, 5-50. https://doi.org/10.7203/CIRIEC-E.93.12901

Civil action No14.(2014). Class action complant jury trial demanded. caso1:14-cv-09662-JSR 12/08/2014. Page 1 of 39. United States Disthrict court. Southern District Of New York 
Contraloría General de la Republica de Perú, (2018). Nota de prensa N625-2018-CG: contraloría identifica riesgos en proyecto línea 2 del metro de Lima que pueden retrasar inicio del servicio.

http://www.contraloria.gob.pe/wps/wcm/connect/cgrnew/as_contraloria/prensa/notas_de_prensa/2018 /lima/np_625-2018-cg

Corral Y. (2009). Validez y confiabilidad de los instrumentos de investigación para la recolección de datos. Revista Ciencias de la Educación, 19(33), 228-247.

Correa, M. Flynn, S. Y Amit, A. (2004) Responsabilidad social corporativa en América Latina: una visión empresarial. División de Desarrollo Sostenible y Asentamientos Humanos. Santiago de Chile, abril de 2004. Recuperado de : https://repositorio.cepal.org/bitstream/handle/11362/5621/1/S044214_es.pdf

Cortes I, (19 de enero de 2017). Las preguntas claves sobre el escándalo de corrupción de Odebrecht. El Tiempo. Recuperado de https://www.eltiempo.com/justicia/cortes/claves-sobre-escandalo-odebrecht-encolombia-45887

Delfina, E. (diciembre 23 de 2018). Odebrecht y lecsa frenan el acuerdo para que Brasil entregue pruebas de sobornos. Perfil. Recuperado de https://www.perfil.com/noticias/sociedad/odebrecht-y-iecsa-frenan-elacuerdo-para-que-brasil-entregue-pruebas-de-sobornos1.phtml

Delfino, E. (2018) Revelan que Odebrecht habría pagado sobornos por US\$ 35 millones a funcionarios argentinos. Radio perfil. Recuperado de: https://www.perfil.com/noticias/politica/revelan-que-odebrechthabria-pagado-sobornos-por-us-35-millones-a-funcionarios-argentinos.phtml El Universo, (2017). Recuperado de: https://www.eluniverso.com/servicios/archivo/2017/08/03

Dinero. (Octubre 23 de 2017). PricewaterhouseCoopers "tira la toalla" y no va más como revisor de Odebrecht.

Dinero. Descargado de https://www.dinero.com/economia/articulo/pricewaterhousecoopers-renuncia-a-serrevisor-de-odebrecht/251430

Espinoza Quinn, William. (2016). La tecnología de la información como herramienta construccionista para el auditor financiero hibrido. Fides et Ratio - Revista de Difusión cultural y científica de la Universidad La Salle en

Fernandez, L, y Gutiérrez, M. (2013). Social, Economic and Environmental Welfare for Present and Future Generations. Información tecnológica, 24(2), 121-130. https://dx.doi.org/10.4067/S071807642013000200013

Franco Campos, D. P., Arrieta Hernandez, N. S., \& Muñoz Hernández, H. (2015). Formación del juicio de valor en la medición y valoración contable desde la perspectiva de responsabilidad social. Estrategia, 1(1), 35-47. Recuperado a partir de http://estrategia.unisinu.edu.co/index.php/estrat/article/view/8

Franco Ruiz, (2016). Sociodicea contable en evolución: del saber estratégico a la crisis de la representación. Revista Científica General José María Córdova, 14(18), 269-307. Disponible en: https://www.redalyc.org/articulo.oa?id=4762/476255360014

Franco, R. (2018). Pensamiento contable latinoamericano : entre colonialismo intelectual y ciencia propia. Revista Científica General José María Córdova, 16, 133-161. https://doi.org/dx.doi.org/10.21830/19006586.325

Galindo Cárdenas, S. G., \& Franco Campo, D. P. (2016). Las NAFMA, Normas de Auditoría Financiera y Medio Ambiente: Fundamento desde el paradigma sistémico ecológico. Estrategia, 2(1), 60-72. Recuperado a partir de http://estrategia.unisinu.edu.co/index.php/estrat/article/view/32 
Hernández Royett, J., Franco, D., Canabal Guzmán, J., Sánchez Otero, M., \& D’Andreis Zapata, A. (2017). La auditoría ambiental, una atribución de las funciones del revisor fiscal. Aglala, 8(1), 219-242. https://doi.org/10.22519/22157360.1033

Hernández Sampieri, R., Fernández, C., \& Baptista, P. (2014). Metodología de la Investigación. México D.F.: McGraw-Hill

Hernández-Royett, J. (2016). Conducta de los contadores públicos que vulneran el código de ética profesional. Enfoque Disciplinario, 1(1), 41-53. Recuperado a partir de http://enfoquedisciplinario.org/revista/index.php/enfoque/article/view/8

Hernández-Royett, J., \& González-Díaz, R. R. (2016). Enfoques de investigación en la contabilidad. Estrategia, 2(1), 87-100. Recuperado a partir de http://estrategia.unisinu.edu.co/index.php/estrat/article/view/29

IFAC. (2016). La profesión contable: lucha contra el fraude y la corrupción, Carta abierta a Su Santidad el Papa Francisco

IFAC. (2018). El Código Internacional de Ética para profesionales de la contabilidad: Áreas centrales clave para SME y SMP. Recuperado de https://www.ifac.org/knowledge-gateway/building-trust-ethics/discussion/elc-digo-internacional-de-tica-para

International Educación Standards/IES 6, (2015) Internacional Accounting Education Standars Board. Handbook of international education pronouncements 2015 edition. Recuperado de:

https://www.ifac.org/system/files/publications/files/IAESB-2015-Handbook_0.pdf

Lang, M., Karmanska, A. \& Jarvis, R. (2017). Contaduría y ética: La presión que experimenta el contador profesional. Instituto Nacional de Contadores Públicos, Boletín Virtual INCP No. 134. Recuperado de https://www.incp.org.co/contaduria-etica-la-presion-experimenta-contadorprofesional/

Linares Rodríguez, M., \& Suárez Rico, Y. (2017). Competencias del contador público: Una mirada desde la Educación Superior y los requerimientos de las PyME comerciales en Bogotá. Revista Latinoamericana de Investigación en Organizaciones, Ambiente y Sociedad., 8(10), 149-176. Recuperado de https://revistas.elpoli.edu.co/index.php/teu/article/view/1206

Lukomski, A., y Mancipe, E. (2008). El paradigma emergente y su impacto en la investigación epistemológica de las ciencias sociales. Hallazgos, 10(10), 133-145. Retrieved from http://www.redalyc.org/pdf/4138/413835171010.pdf

Martínez-Ferrero, J., Vaquero-Cacho, Luis, Cuadrado-Ballesteros, B., García-Sánchez, I. (2015). El gobierno corporativo y la responsabilidad social corporativa en el sector bancario: el papel del consejo de administración. Investigaciones Europeas de Dirección y Economía de la Empresa. 21(3), 129-138 ISSN: 1135-2523. Disponible en: http://www.redalyc.org/articulo.oa?id=274146982004

Mejía, E., Mora, G., Montes, C., Montilla, O. (2014). Marco conceptual de la biocontabilidad. Sinapsis, 6(6), 147178

Morelo, D. Y Torres, D. (2016) Responsabilidad social laboral en educación contable (RSLEC)un análisis fenomenológico interpretativo. Estrategia ISBN 1692-0597. Recuperado de: http://estrategia.unisinu.edu.co/index.php/estrat/article/view/28/38

Norma internacional de auditoría 315. Identificación y valoración de los riesgos de incorrección material mediante el conocimiento de la entidad y de su entorno. (octubre 15 de 2013). Recuperado de http://www.icac.meh.es/NIAS/NIA\%20315\%20p\%20def.pdf

Norma internacional de auditoría 550. Partes vinculadas. (diciembre 15 de 2013). Recuperado de http://www.icac.meh.es/NIAS/NIA\%20550\%20p\%20def.pdf 
Norma Internacional De Auditoría 620 Utilización Del Trabajo De Un Experto Del Auditor (NIA-ES 620) (2013). adaptada para su aplicación en España mediante Resolución del Instituto de Contabilidad y Auditoría de Cuentas, de 15 de octubre de 2013

OCDE. (2015). Recomendación del consejo sobre gobernanza presupuestaria. V, 1-19.

Ongay de Felipe, Íñigo (2010). Reseña de "El fundamentalismo democrático. La democracia española a examen" de Gustavo Bueno. Nómadas. Critical Journal of Social and Juridical Sciences, 28(4). Disponible en: https://www.redalyc.org/articulo.oa?id=181/18118913024

Organización Odebrecht. (2018). Recuperado de https://www.odebrecht.com/es/organizacionodebrecht/odebrecht-en-el-mundo

Ovallos, D., Álvarez, A. y Miranda, A. (2017). Ética y Responsabilidad Social del Contador frente a las Normas Internacionales de Información Financiera (NIIF) en Colombia. Un Análisis Prospectivo. Revista Espacios 38 (37) Año 2017. p14

Perea, C. (Noviembre 29 de 2018). Investigación de caso Odebrecht en Panamá tiene un 80\% de avance, 255 millones recuperados. Nacionales. Recuperado de http://www.telemetro.com/nacionales/InvestigacionOdebrecht-Panama-culminar-trimestre_0_1195381202.html

Perfil. (diciembre 22 de 2016). Las ocho obras de Odebrecht en Argentina que investiga la Justicia. Recuperado de https://www.perfil.com/noticias/politica/las-ocho-obras-de-odebrecht-en-argentina-que-la-justiciainvestiga.phtml

Robazo, E., (2017). El fraude contable : una evidencia empírica. Tesis de doctorado. Universidad de Extremadura

Roncancio, A., Mira, G. y Muñoz, N. (2017). Las competencias en la formación del profesional contable : una revisión de las posturas institucionales y educativas en Colombia, XXV (2), 83-103. Recuperado de http://www.scielo.org.co/pdf/rfce/v25n2/0121-6805-rfce-25-02-00083.pdf

Sanroman, R., González, I. y Villa, M. (2015). Los principios éticos y las obligaciones civiles. Boletín Mexicano de Derecho Comparado, 48(142), 313-338. https://doi.org/10.22201/iij.24484873e.2015.142.4922

Semenaeconomica.com. (13 de enero de 2019). Línea 1 del Metro: se identificó perjuicio de US\$20.6 millones en el tramo II. http://semanaeconomica.com/article/sectores-y-empresas/conectividad/326271-linea-1del-metro-se-identifico-perjuicio-de-us20-6-millones-en-el-tramo-ii/

Transparencia Venezuela (2018). Informe Odebrecht 2018. Venezuela https://transparencia.org.ve/project/odebrecht-informe-odebrecht-2018/

Vargas, C. (noviembre 25 de 2018). Las auditorías realizadas a Odebrecht. El espectador. Descargado de https://www.elespectador.com/noticias/judicial/las-auditorias-realizadas-odebrecht-articulo-825663

Vargas, R., Cruz, E., Gatica, L., \& García, P. (2015). El Contador Público como líder del cambio social en el nuevo escenario educativo mexicano. Revista Iberoamericana de Ciencias 2(4). P,167-177

Venegas, A. (24 de noviembre de 2018). Acciones del Grupo Aval extienden sus pérdidas con caída de las bolsas internacionales. La república. Editorial.

Esta obra está bajo una Licencia Creative Commons Attribución-NoCommercial 4.0 International

(cc) BY-NC 